\title{
Regulation of Granulocyte Function by Hyaluronic Acid
}

\author{
IN VITRO AND IN VIVO EFFECTS \\ ON PHAGOCYTOSIS, LOCOMOTION, AND METABOLISM
}

\author{
Lena Håkansson, Roger Hällgren, and Per Venge, Departments of \\ Clinical Chemistry and Internal Medicine, University Hospital, S-750 14, \\ Uppsala, Sweden
}

\begin{abstract}
A B S T R A C T Hyaluronic acid (HA) stimulated the function of polymorphonuclear leukocytes (PMN) both in vitro and in vivo. Stimulation in vitro was achieved by the incubation of PMN and HA in heparinized whole blood at concentrations of HA between 5 and $500 \mu \mathrm{g} /$ liter. The stimulation of the PMN function was demonstrated by an increased rate of phagocytosis of complement- and/or immunoglobulin (Ig)G-coated latex particles, increased adherence to nylon wool, increased random migration and chemotactic response, increased chemiluminescence during phagocytosis, and raised levels of intracellular ATP. The effect of HA in vivo was demonstrated, after subcutaneous administration of HA (5-20 mg) to healthy volunteers, by an enhanced rate of phagocytosis of the subsequently isolated neutrophils. The duration of the effect of one administration was $\sim 1 \mathrm{wk}$ with maximum effect on days $2-4$. HA injections to patients with increased susceptibility to bacterial infections and impaired neutrophil function demonstrated an enhanced neutrophil function also in these individuals. HA may therefore be a new principle by which resistance to infections can be enhanced.
\end{abstract}

\section{INTRODUCTION}

An optimal function of the polymorphonuclear leukocytes $(\mathrm{PMN})^{1}$ is essential for host resistance to bacterial infections. Therefore much effort has been spent in the search for agents that could enhance the PMN function and correct defects found in many patients with extreme infection propensity. The idea that hyaluronic acid (HA) might be such an agent has occurred from our experimental studies of this glucosamino-

Address reprint requests to Dr. Hällgren.

Received for publication 7 October 1979 and in revised form 8 April 1980.

${ }^{1}$ Abbreviations used in this paper: HA, hyaluronic acid; PMN, polymorphonuclear leukocytes. glycan and its biological actions on cells of the lymphomyeloid system.

In a recent report (1) we were able to demonstrate a stimulatory effect of HA on PMN phagocytic function. This stimulation was achieved with a co-opsonic effect of HA, as HA increased the phagocytic rate of serumopsonized immunoglobulin (Ig)G-coated particles by a mechanism directed against the serum opsonins on the particles. The concentration of HA (1-10 mg/liter) that was needed to obtain this activity, however, greatly exceeded the supposed concentration of native $\mathrm{HA}$ in the circulation (2). In the present report we have extended our investigation of the effect of HA on PMN function and describe a stimulatory effect of HA achieved by a completely different mechanism and at concentrations likely to be found in the circulation. The in vitro findings suggested possible therapeutic effects of $\mathrm{HA}$ as a regulator of resistance to infections. As will be shown, in vivo trials on normals and patients with increased infection-propensity and defective neutrophil function, have supported this suggestion.

\section{METHODS}

Patients. The patient group consisted of 10 patients with impaired host resistance defined as extreme propensity for bacterial infections and impaired phagocytic activity of their PMN (i.e., a phagocytic rate $<0.45 \mathrm{~min}^{-1}$, as measured with IgG-coated latex particles [3]). Seven of the patients were heat burn patients. Three patients had had repeated pulmonary and septic bacterial infections during the last years.

Isolation of PMN. PMN were isolated from heparinized venous blood (Venoject, Terumo Corporation, Tokyo, Japan). Heparinized blood was mixed with an equal volume of dextran solution (20 g/liter) (Pharmacia Fine Chemicals, Uppsala, Sweden) and the erythrocytes were allowed to sediment for $30 \mathrm{~min}$ at room temperature. The leukocyte-rich supernate was collected and centrifuged at $160 \mathrm{~g}$ for $5 \mathrm{~min}$. The leukocytes were thereafter washed twice with Ringerdex (Pharmacia Fine Chemicals). The remaining erythrocytes were hemolyzed with hypotonic saline for $30 \mathrm{~s}$. After an additional wash, the leukocytes, as a highly concentrated cell suspension, were left at $+4^{\circ} \mathrm{C}$ for $30-45 \mathrm{~min}$. With this treatment the PMN 
aggregated slightly and separated visibly by sedimentation from the rest of the leukocytes. The purity of PMN in the final suspension was $90 \pm 5 \%$ (SD). PMN used for the phagocytosis assay, measurements of chemiluminescence and ATP content were diluted to a final concentration of $2 \times 10^{9} \mathrm{PMN} /$ liter in Ringerdex with glucose added (6.94 mmol/liter). For measurement of PMN migration the washed leukocyte suspension obtained after the hypotonic lysis was used. The concentration of PMN was adjusted to $1.5 \times 10^{9} \mathrm{PMN} / \mathrm{liter}$ with Gey's solution.

Phagocytosis was measured kinetically using an electronic particle counter (4). The modified assay was performed in Ringerdex solution with glucose $(6.9 \mathrm{mmol} / \mathrm{liter})$. The particles (polyvinyl-toluene latex, volume; $4.38 \times 10^{-15}$ liter, Coulter Electronics Ltd., Dunstable, England) were coated with human IgG as previously described (2). Such IgG-coated particles were also incubated in $20 \%$ fresh normal human serum at $37^{\circ} \mathrm{C}$ for $10 \mathrm{~min}$. The serum was washed away by two subsequent washes in assay buffer. To such particles, which were called serum-opsonized particles, the complement components $\mathrm{C} 3$ and $\mathrm{C} 4$ were bound (1). The initial rate of phagocytic uptake was calculated as previously described $(3,4)$ and expressed in minutes ${ }^{-1}$. The coefficient of intraday variation of the assay was $8 \%$, and of the intra- and interday variation, $14 \%$.

In some experiments phagocytosis of IgG-coated latex particles by nonisolated granulocytes was morphologically assessed. $0.2 \mathrm{ml}$ of fresh, heparinized venous blood was incubated during constant rotation for $60 \mathrm{~min}$ at $37^{\circ} \mathrm{C}$ with $0.2 \mathrm{ml}$ of IgG-coated latex particles diluted in Ringerdex. The approximate particle:granulocyte ratio was 10:1. Smears of cellparticle incubates were prepared and stained with Giemsa (Merck Sharp and Dohme AG, Darmstadt, West Germany) and examined by light microscopy. The number of PMN containing $0,1-10$, or $>10$ particles/cell was calculated.

Adherence of PMN was measured with the nylon wool assay described by MacGregor et al. (5). $50 \mathrm{mg}$ spun nylon wool (Leuko-pak) obtained from Travenol Laboratories, Inc. (Brussels, Belgium) was packed into a siliconized Pasteur pipette to a column length of $15 \mathrm{~mm}$. A volume of $1 \mathrm{ml}$ of heparinized venous blood was applied on the top of the column and allowed to flow through. The percentage of PMN adhering to the column was calculated from the PMN counts in the blood before and after the passage through the column.

Random migration and chemotaxis. Migration of PMN was assayed by means of the leading-front technique (6), using a modified Boyden chamber (7). The microfilters (Millipore Corp., Molsheim, France) used had a pore size of $3 \mu \mathrm{m}$ and were $\sim 150 \mu \mathrm{m}$ thick. Casein (Merck Sharp and Dohme AG) at a concentration of $1 \mathrm{~g} /$ liter was used as attractant, measuring chemotaxis. Random migration was assayed as the migration against Gey's solution. The incubation time was $75 \mathrm{~min}$. The filters were fixed with $95 \%$ ethanol and the leukocytes stained with Mayer's Hämalaun-Lösung (Merck Sharp and Dohme AG).

Chemiluminescence produced by isolated PMN during phagocytosis of serum-opsonized zymosan particles was measured by means of the Lumac cell tester (Lumac Systems, Inc., Basel, Switzerland) and with reagents purchased from the manufacturer. Luminol (Lumac Systems, Inc.) was used to amplify chemiluminescence and was used at concentration 0.2 $\mathrm{g} /$ liter dissolved in $0.1 \mathrm{M}$ borate buffer, $\mathrm{pH}$ 8.2. Isolated PMN in Ringerdex-glucose buffer $\left(2.0 \times 10^{9}\right.$ cell/liter $)$ were exposed to serum-coated zymosan (Schwarz/Mann, Div. Becton, Dickinson \& Co., Orangeburg, N. Y.) at a final concentration of $0.4 \mathrm{~g}$ /liter. The incubation was performed at $37^{\circ} \mathrm{C}$ during constant magnetic stirring $(1,600 \mathrm{rpm})$. Measurements of chemiluminescence were made on $100 \mu \mathrm{l}$ cell-zymosan suspension withdrawn from the incubate at 1-min intervals. Further details of the measurements are presented elsewhere
(8). The results presented are the maximum chemiluminescent responses obtained during the phagocytosis.

The intracellular content of ATP in isolated PMN at rest was measured by means of the luciferin-luciferase system, using a Lumac cell tester (8).

$H A$. The sodium salt of HA prepared from rooster comb was used. The sterile, pyrogen-free solution (as tested by rabbit pyrogen test and limulus lysate assay) of HA of $M_{r}$ (average molecular weight) $2 \times 10^{6}$ or $0.2 \times 10^{6}$ was obtained from Pharmacia Fine Chemicals.

In vitro effect of HA. Blood specimens were obtained from healthy volunteers and patients with impaired host resistance. HA was added to heparinized blood to a final concentration of $0.5-1,000 \mu \mathrm{g} / \mathrm{liter}$. After incubation at room temperature for $30 \mathrm{~min}$ the PMN were isolated as previously described. The isolated PMN were analyzed for their phagocytic activity, migrating activity, intracellular ATP content, and chemiluminescence.

In vivo effects of $\mathrm{HA}$. Subcutaneous injections of $\mathrm{HA}$ $\left(M_{\mathrm{r}} 2 \times 10^{6}\right), 0.5-2 \mathrm{ml}(10 \mathrm{mg} / \mathrm{ml})$, were given once or repeatedly to volunteers and patients. Heparinized blood was taken from the injected individuals each or every 2 nd $d$ and the phagocytic activity, intracellular ATP content, and chemiluminescent production of PMN isolated as above, were tested.

Student's paired $t$ test was used for statistical analyses.

\section{RESULTS}

The effect of HA on the initial rate of phagocytosis. The addition of HA $\left(M_{\mathrm{r}} 2 \times 10^{6}\right)$ to heparinized blood of healthy individuals induced a stimulation of the activity of isolated PMN. The incubation time of $\mathrm{HA}$ with whole blood was 30 min since a time dependency was observed with the maximum stimulatory effect after 20-40 min of preincubation. Altogether, 114 blood specimens obtained from 13 healthy volunteers were investigated after preincubation with various concentrations of HA $(0.5-1,000 \mu \mathrm{g} / \mathrm{liter})$. The HA concentration with the maximum stimulatory effect averaged $50 \mu \mathrm{g} / \mathrm{liter}$, varying between different cell populations from 5 to $100 \mu \mathrm{g} / \mathrm{liter}$. The maximum degree of enhancement $(P<0.001)$ was also individual and varied between 125 and 329 (average, 179)\% in relation to incubated controls (100\%). Blood specimens of two individuals were examined repeatedly to illustrate the dose-dependent stimulation induced by HA (Fig. 1). The size dependence of the stimulatory effect of HA was tested by incubations made with hyaluronidasedigested HA. The stimulatory activity was also obtained with $\mathrm{HA}$ of a $M_{\mathrm{r}}$ of $0.2 \times 10^{6}$.

Our kinetic measurements of phagocytosis were based on an indirect technique and therefore controls were made with light microscopy. After 5 min of incubation, cell smears were examined as previously described (4). The small proportion of particles merely adherent to the cells was quite similar with or without HA present. This indicates that the stimulated phagocytic rate mediated by HA was not only a consequence of increased passive adherence of particles to the cell surface. 


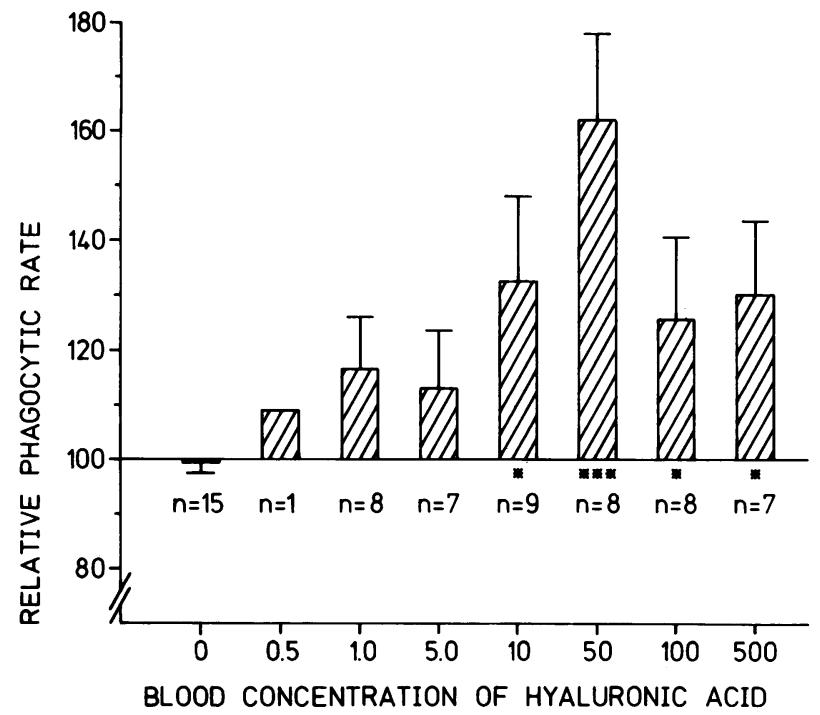

FIGURE 1 The uptake rate of IgG-coated latex particles in buffer medium by PMN isolated from heparinized blood preincubated for 30 min with various concentrations of HA (expressed in micrograms per liter). The blood was obtained from two healthy individuals. The change of the phagocytic rate by influence of $\mathrm{HA}$ is expressed in relation to incubated controls $(100 \%)$. The bars represent the mean \pm SEM of the measurements. The number of experiments $(n)$ and the results of statistical analyses $(*=P<0.05, * *=P<0.01, * * *=P$ $<0.001)$ are given in the figure.

To study the effect of HA on the phagocytic function of nonisolated PMN we incubated heparinized blood and IgG particles and assessed the particle uptake after $60 \mathrm{~min}$ of incubation. In the blood samples preincubated for $30 \mathrm{~min}$ at $22^{\circ} \mathrm{C}$ with $\mathrm{HA}$ at concentrations between 5 and $50 \mu \mathrm{g} /$ liter, a significantly $(P<0.01)$ increased proportion of PMN had phagocytized $>10$ particles/cell (Table I) with a concomitant reduction of cells with 0 or 1-10 particles/cell. This indicates an augmentation of the phagocytic capacity of the PMN population in whole blood.

The effect of HA on PMN adherence. The adherence to nylon wool of PMN in heparinized whole blood was stimulated after preincubation of blood with HA (Fig. 2). Maximum stimulation was obtained at a HA concentration of $50 \mu \mathrm{g} / \mathrm{liter}$. The average of the maximum stimulation was $175 \%(P<0.01)$ as compared with the incubated controls (100\%).

The effect of HA on random migration and chemotaxis. The incubation of heparinized whole blood with HA resulted in a stimulation of both the chemotactic response and the random migration of the later isolated PMN (Fig. 3). Maximum stimulation of chemotaxis was obtained at a $\mathrm{HA}$ concentration of $10 \mu \mathrm{g} / \mathrm{liter}$ (range 5-50 $\mu \mathrm{g} / \mathrm{liter}$ ) and of random migration at 50 $\mu \mathrm{g} /$ liter (range 10-100 $\mu \mathrm{g} /$ liter). The maximum stimulation averaged $156 \%$ (range 136-213\%) for chemotaxis $(P<0.001)$ and $150 \%$ (range 133-200\%) for random migration $(P<0.01)$ as compared with incubated controls (100\%).

Isolated granulocytes $\left(1.5 \times 10^{9} \mathrm{PMN} /\right.$ liter $)$ were also incubated at $22^{\circ} \mathrm{C}$ for $30 \mathrm{~min}$ in $80 \%$ fresh autologous serum containing $\mathrm{HA}$ at the same concentrations as tested in the experiments illustrated in Fig. 3. After the preincubation the PMN were washed once in saline and finally diluted to a cell concentration of $1.5 \times 10^{9}$ $\mathrm{PMN} /$ liter. By this procedure and based on six experiments at each HA concentration tested, significant stimulation of random migration and chemotaxis was found at $\mathrm{HA}$ concentrations between 5 and $50 \mu \mathrm{g} / \mathrm{liter}$. The maximum stimulation found at $50 \mu \mathrm{g} / \mathrm{liter}$ was for random migration on average $123 \pm 0.5$ (SEM) \% ( $P$ $<0.001)$ and for chemotaxis $119 \pm 6(\mathrm{SEM}) \%(P<0.01)$ as compared with incubated controls (100\%). When corresponding experiments were performed in $10 \%$ autologous serum no significant stimulation of random migration or chemotaxis was observed.

TABLE I

Morphological Assessment of Phagocytosis by Granulocytes and the Influence of $\mathrm{HA}^{*}$

\begin{tabular}{ccll}
\hline $\begin{array}{c}\text { Amount of } \\
\text { HA added }\end{array}$ & $\begin{array}{c}\text { Percentage } \pm \text { SEM of } \\
\text { PMN with no particles }\end{array}$ & $\begin{array}{c}\text { Percentage } \pm \text { SEM of } \\
\text { PMN with 1-10 particles }\end{array}$ & $\begin{array}{c}\text { Percentage } \pm \text { SEM of PMN } \\
\text { with }>10 \text { particles/cell }\end{array}$ \\
\hline mg/liter & & & \\
None & $15 \pm 2$ & $53 \pm 1$ & $33 \pm 3$ \\
1 & $10 \pm 3$ & $44 \pm 2$ & $44 \pm 3$ \\
5 & $9 \pm 4$ & $40 \pm 6$ & $51 \pm 2(P<0.01) \ddagger$ \\
10 & $10 \pm 2$ & $38 \pm 3(P<0.01)$ & $52 \pm 3(P<0.01)$ \\
50 & $7 \pm 2(P<0.05)$ & $40 \pm 1(P<0.001)$ & $53 \pm 3(P<0.01)$ \\
100 & $8 \pm 3$ & $50 \pm 6$ & $42 \pm 6$ \\
500 & $10 \pm 1$ & $59 \pm 2$ & $31 \pm 2$ \\
\hline
\end{tabular}

* Heparinized whole blood was preincubated for $30 \mathrm{~min}$ at $22^{\circ} \mathrm{C}$ with various amounts of HA. Results are based on four different experiments at each HA concentration. † Significance was tested against incubated controls. 
The effect of HA on cellular ATP content and chemiluminescence. HA was incubated with heparinized blood as above. The changes in chemiluminescence of phagocytizing PMN and ATP content of resting cells induced by preincubation of blood withHA, are shown in Fig. 4. The dose-dependent increments of these two parameters coincided. The maximum stimulatory concentration of $\mathrm{HA}$ averaged $50 \mu \mathrm{g} /$ liter (range 5-100 $\mu \mathrm{g} / \mathrm{liter}$ ) as based on analyses of 33 blood specimens obtained from two volunteers. The mean stimulation of chemiluminescence was 157 (range 129-226) \% ( $P$ $<0.001$ ) and of ATP content 170 (range 156-193) \% $(P<0.001)$, as compared with controls $(100 \%)$.

Subcutaneous administration of HA. Subcutaneous injections of 5-10 mg HA were given to healthy subjects $(n=6)$ and to patients $(n=10)$ with decreased resistance to bacterial infections and impaired phagocytic activity. Heparinized venous blood was taken from the injected individuals each or every second day and the function of the isolated PMN was tested. The phagocytic rate of PMN measured with IgG-coated latex particles was stimulated in all injected normal subjects. The stimulation was evident $1 \mathrm{~d}$ after injection and the duration of stimulation was $\sim 1 \mathrm{wk}$ (Fig. 5). The maximum stimulation was obtained after $2-4 \mathrm{~d}$ (Figs. 5 and 6). Leukocytosis or fever were not observed after injection. No local reaction was noted at the site of injection. The protuberance after HA-injection lasted for almost $1 \mathrm{wk}$.

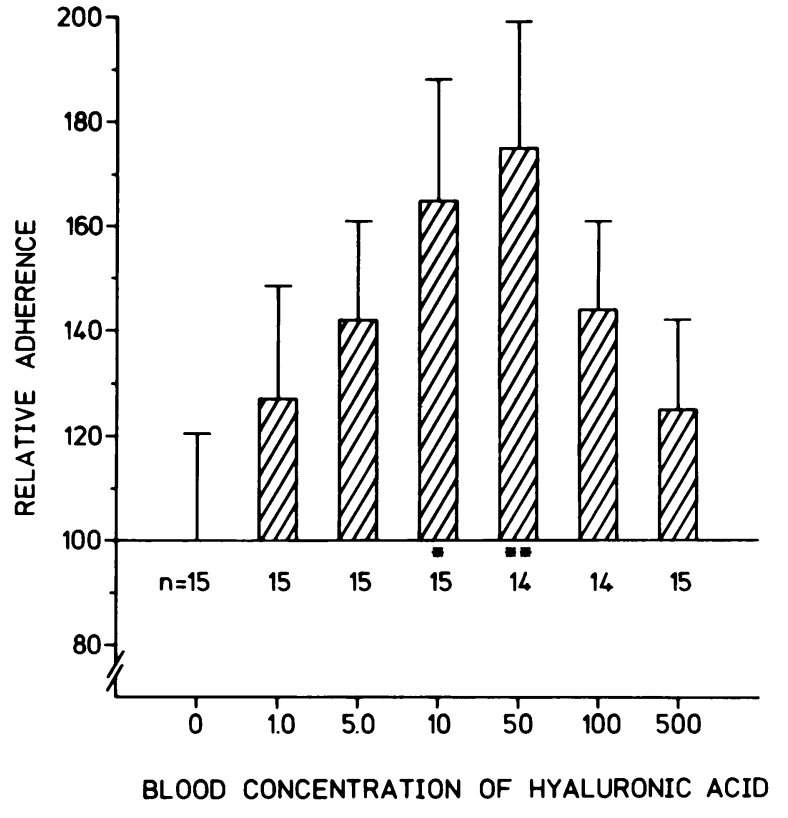

FigURE 2 The adherence of PMN in heparinized whole blood to nylon wool and the influence of HA. The blood samples obtained from two healthy individuals were preincubated with various concentrations of $\mathrm{HA}$ for $30 \mathrm{~min}$ at $22^{\circ} \mathrm{C}$ before tested (expressed in micrograms per liter). The changes in adherence are expressed in relation to incubated controls $(100 \%)$. The bars represent the mean $\pm S E M$ of the measurements. The number of experiments $(n)$ and the results of statistical analyses $(*=P<0.05 ; * *=P<0.01)$ are shown.

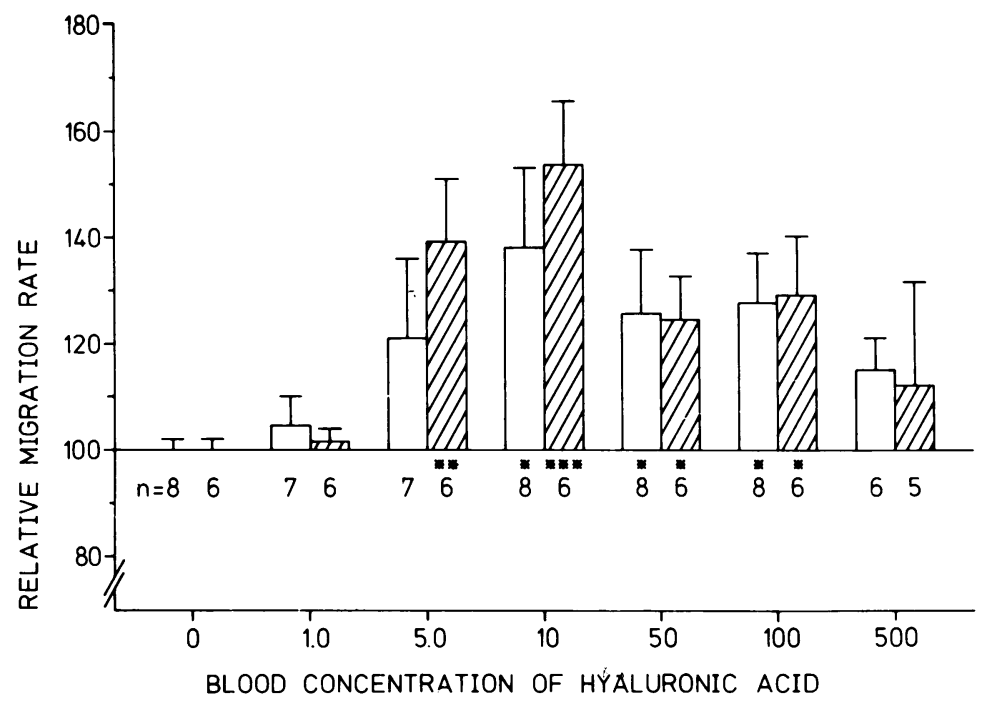

FIGURE 3 The migration of PMN isolated from heparinized blood preincubated for 30 min with various concentrations of HA. The blood was obtained from four healthy individuals. Random migration $(\square)$ was measured as the migration towards Gey's solution and chemotaxis $(\mathbb{Z})$ as the migration toward casein ( $1 \mathrm{~g} / \mathrm{liter}$ ). The change of the migration rates by influence of $\mathrm{HA}$ is expressed in relation to incubated controls (100\%). The bars represent the mean $\pm \mathrm{SEM}$ of the measurements. The number of experiments $(n)$ and the results of statistical analyses $(*=P<0.05, * *=P<0.01, * * *=P<0.001)$ are given. 


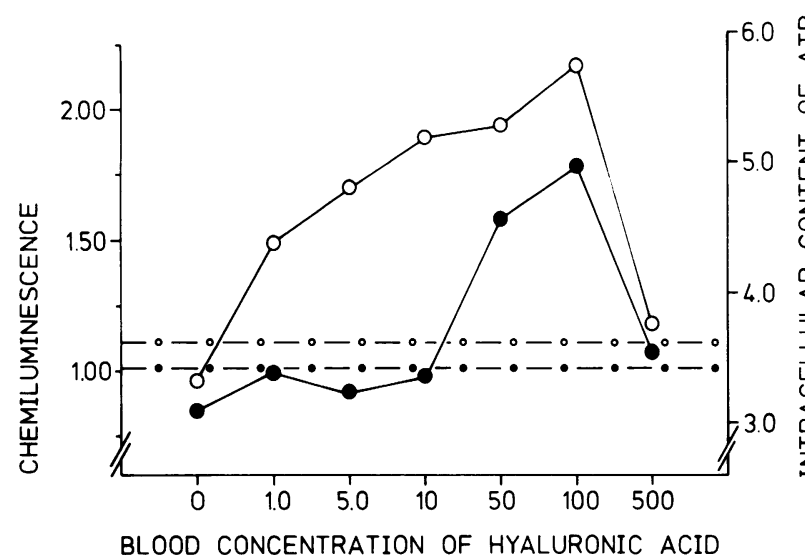

FIGURE 4 Intracellular ATP content of PMN (expressed in femtomoles per leukocyte) (O) and the relative chemiluminescence produced by phagocytizing PMN (O) isolated from heparinized normal blood that had been incubated with various amounts of HA for $30 \mathrm{~min}$ (expressed in micrograms per liter). The broken horizontal lines represent the confidence intervals $(P<0.001)$, related to incubated controls, of the intraday variations for measurements of ATP content $\left(\mathbf{O}_{--} \mathbf{0}\right)$ and chemiluminescence of isolated $\mathrm{PMN}\left(\mathrm{O}_{---} \mathrm{O}\right)$ from healthy controls.

On the basis of these results on normals it was of interest to see whether it was possible to enhance neutrophil function in individuals with an increased propensity for bacterial infections. The 10 patients presented here were chosen to illustrate the effect of HA because they, in addition to their infection propensity, had a defective neutrophil function in terms of phagocytic rate of IgG-coated particles. The neutrophils of all individuals responded by increased rates of phagocytosis of both IgG- and serum-opsonized particles (Fig. 6). Serial determinations of one patient are presented in Fig. 7. Peak phagocytic activities were seen 2-6 d after injection. An increased intracellular content of ATP and enhanced chemiluminescence of isolated PMN were also found after $\mathrm{HA}$ injections (Fig. 8).

\section{DISCUSSION}

Until very recently the specific effects of HA on lymphomyeloid cells only concerned inhibitory biological activities (9-11). However, the concentrations that were used were $\sim 1,000-10,000$ times higher than those used in this investigation. It was also possible to demonstrate an inhibition of the phagocytic activity of PMN at these high HA concentrations. The stimulatory effects of $\mathrm{HA}$ at concentrations $\sim 50 \mu \mathrm{g} /$ liter on PMN function as demonstrated here demand the presence of a cellular or humoral blood component because incubations of isolated PMN with HA under the same ex- perimental conditions did not stimulate the cellular function. Data in this study on chemotaxis and random migration suggest that a serum component is one principle operative in this stimulation.

Because alterations in granulocyte function may be induced during the isolation procedure it cannot be excluded that HA acts by improving cell preservation. However, addition of HA to heparinized venous blood not only stimulated various functions of later isolated PMN but also enhanced the activity of nonisolated granulocytes when tested for phagocytic performance or adhesion to nylon wool. These findings together with the observation that PMN first isolated in the ordinary way later could be stimulated by $\mathrm{HA}$ to enhanced migration, provided fresh serum was present during the incubation, reduce the likelihood that HA exerts its stimulatory action in vitro solely as a cell protector during PMN isolation procedures. The fact that the stimulatory effect of HA did not disappear by degradation of the molecule indicates that the stimulatory effect is not restricted to the intact molecule but may be dependent on a specific structure within the molecule.

The mechanism by which HA stimulated PMN function under the present experimental conditions is not known. The stimulation of both phagocytic activity,

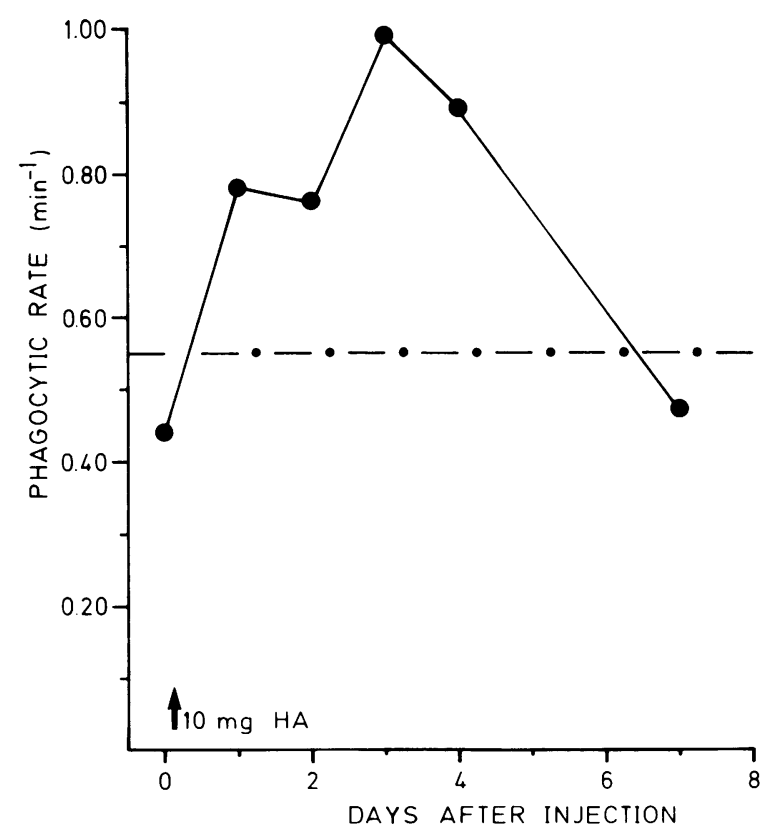

Figure 5 The phagocytic uptake of IgG-coated latex particles by PMN isolated from a healthy individual before and after administration of $10 \mathrm{mg} \mathrm{HA}$ s.c. (- - - ) represents the upper limit of the confidence interval $(P<0.001)$ of the intra- and interday variation related to the measured phagocytic rate before $\mathrm{HA}$ injection. 


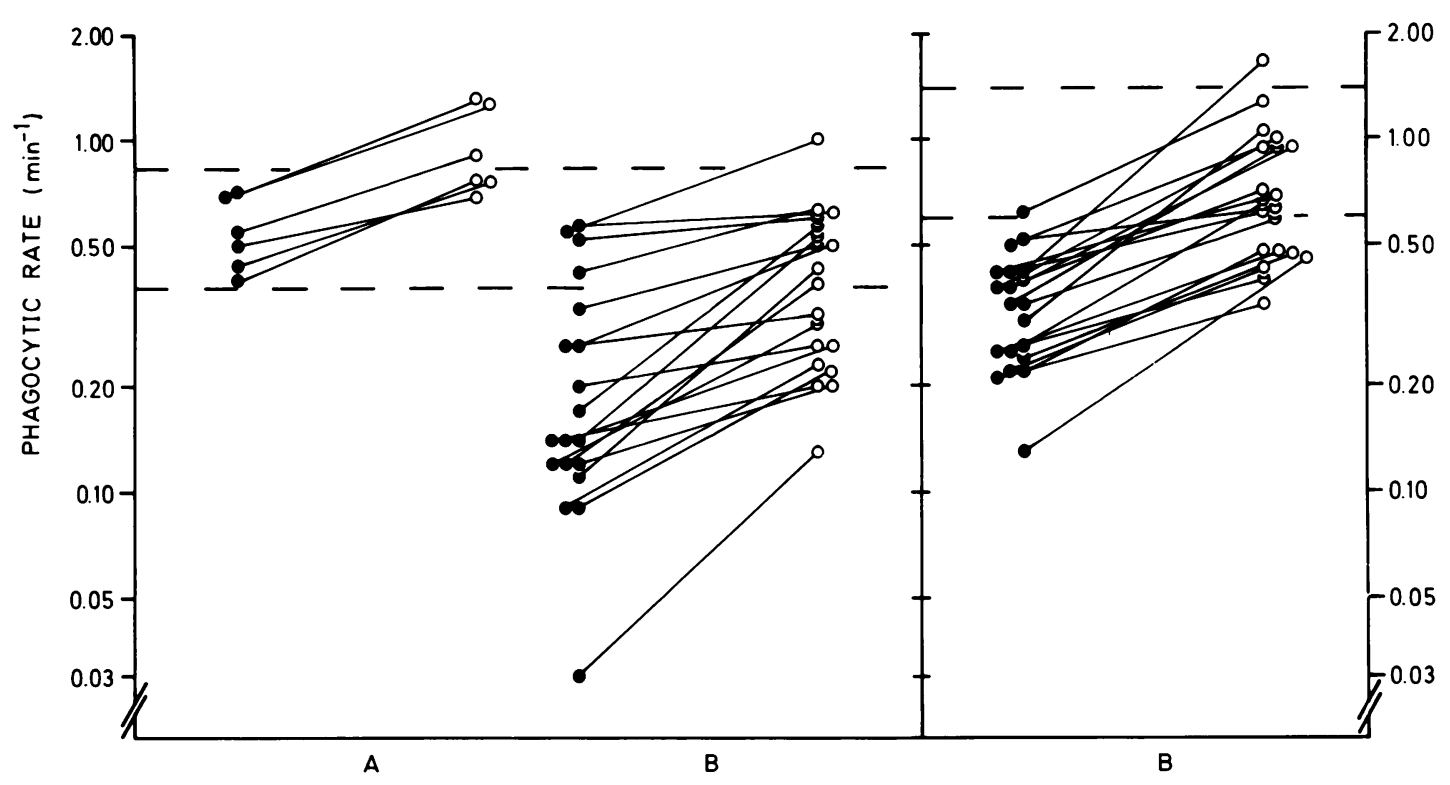

FIGURE 6 The phagocytic uptake of IgG-coated or serum-opsonized particles by isolated PMN obtained from healthy individuals (A) or infection-prone patients (B). The uptake before (O) and the maximum stimulated uptake after subcutaneous injection of HA $(O)$ is illustrated. The enhancement of phagocytic activity was significant $(P<0.001)$ as tested by Student's paired $t$ test.

adherence and locomotion, as well as enhancement of the chemiluminescence suggest a general metabolic activation of the cell. This notion is supported by the finding that in the resting cells ATP was increased after the incubation with HA. The interindividual variability in the maximally effective concentration of HA in vitro has been quite large. The reason for this is unclear but may be related to the availability of the cellular or humoral blood component required to obtain stimulation of neutrophil function. There also seem to be some differences in the maximal response to HA for phagocytosis and locomotion. Generally enhancement of locomotion is achieved at lower HA concentrations than phagocytosis enhancement. This may be due to differences in sensitivity of the assay systems but may also reflect different sensitivities of the two functions to the stimulatory principles studied here. This latter explanation could be a functional mechanism and has also been demonstrated by the use of other means to stimulate neutrophil function $(12,13)$. Enhanced activities of isolated PMN were also observed after subcutaneous administration of HA to healthy volunteers and patients with increased infection propensity and defective neutrophil function. The regular enhancement of neutrophil function after HA injection in the patients could hardly be explained by the natural course of the disease as judged from serial

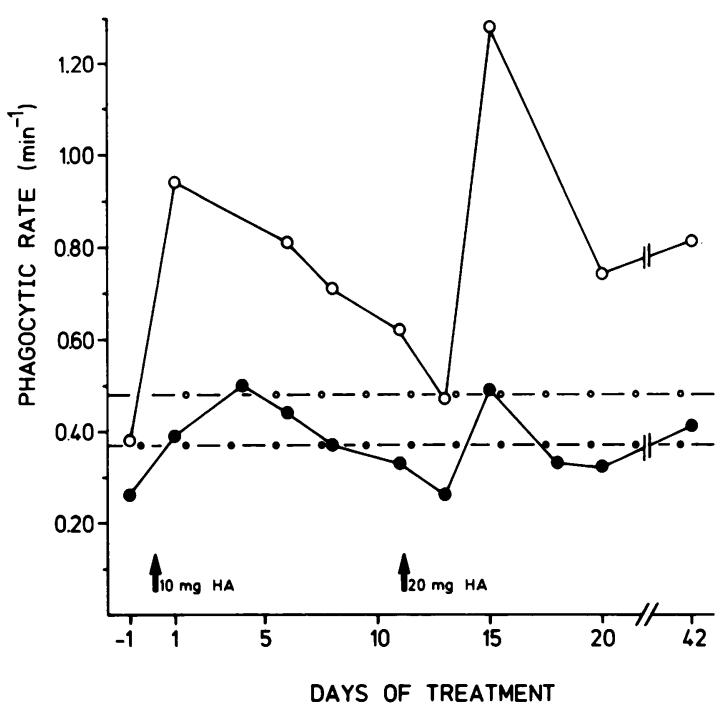

FIGURE 7 The phagocytic uptake of IgG-coated (O) or serumopsonized particles ( $)$ by PMN isolated from the blood of a 38-yr-old woman with repeated and frequent ( $~ 3-4$ episodes/ mo) pulmonary infections with infiltrate. The patient was treated with subcutaneous injections of HA. During the treatment period illustrated she had no infection. The administration of HA is indicated by arrows. The broken horizontal lines represent the upper limits of the confidence intervals $(P<0.001)$ of the intra- and interday variations of phagocytic rate in relation to the first measurements. 


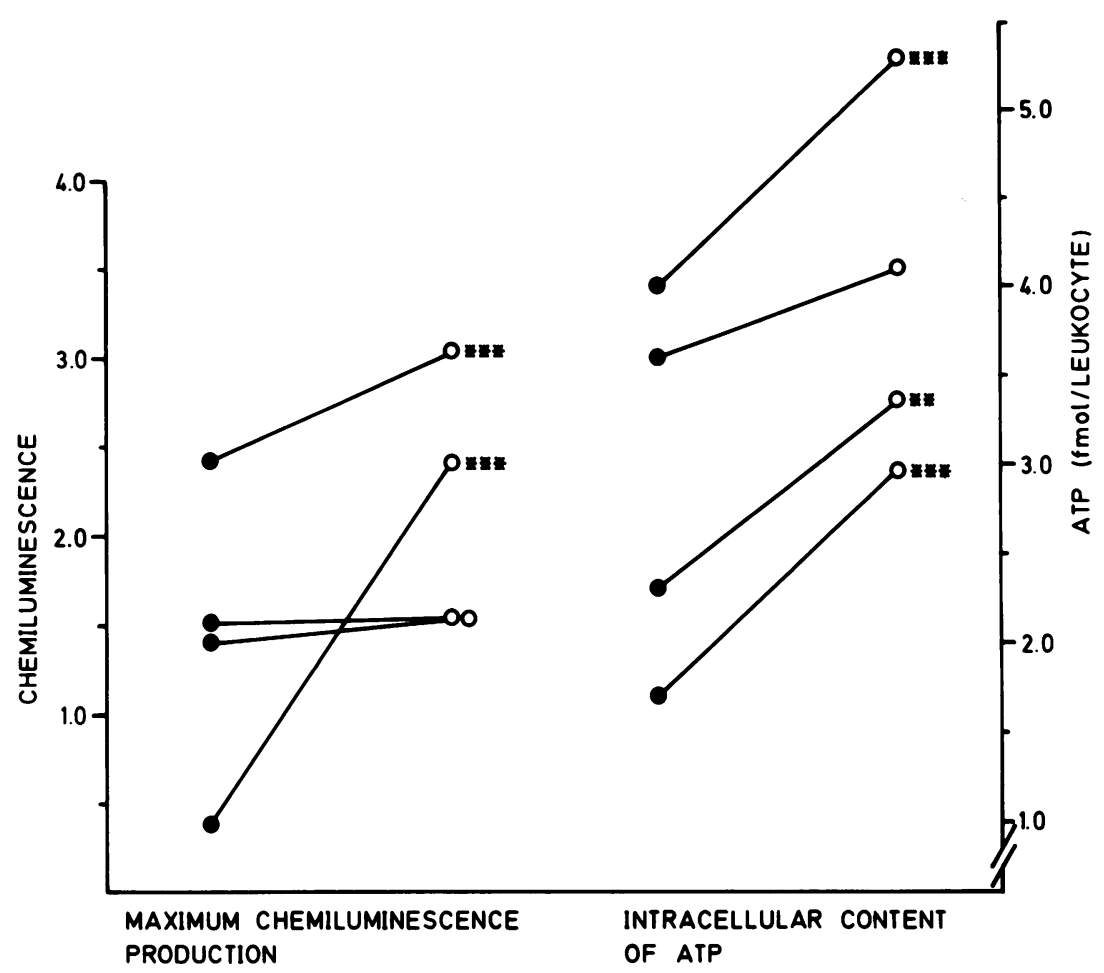

FIGURE 8 Maximum chemiluminescence of phagocytizing PMN and the intracellular content of ATP of PMN obtained from four patients with burns before $(O)$ and after $(O)$ injection of $10-20 \mathrm{mg}$ HA s.c. The significant increases are flagged $(* *=P<0.01, * * *=P<0.001)$.

determinations of neutrophil function in the same patients before HA administration and by follow-up of other patients with burns. ${ }^{2}$

The stimulatory effects of $\mathrm{HA}$ in vitro and the effects in vivo obtained after injection may reflect indentical mechanisms. The fate of HA after subcutaneous injection is obscure but we postulate that HA enters the circulation at a slow rate because the stimulation of the PMN remained for almost $7 \mathrm{~d}$ after injection. No turnover studies of $\mathrm{HA}$ after subcutaneous administration have yet been done. However, the remaining of a noninflamed protuberance at the site of injection for about 1 wk supports the suggestion of a slow release of HA. Based on the assumption that HA is constantly released to the circulation this means that after injection of 10-20 mg HA s.c. $\sim 2 \mathrm{mg}$ of HA may enter the circulation every $24 \mathrm{~h}$ resulting in a contribution to the plasma levels of 250-500 $\mu \mathrm{g} / \mathrm{liter}$. In spite of our lack of knowledge of the turnover rate of $\mathrm{HA}$ in the circulation this rough estimation gives us an idea of the order of magnitude at which HA may appear in the circulation after subcutaneous administration. Our in vitro results with optimal stimulatory HA concen-

${ }^{2}$ Håkansson, L., R. Hällgren, P. Venge, G. Arthursson, and S. Vedung. Submitted for publication. trations in the range between 10 and $100 \mu \mathrm{g} /$ liter may therefore very well reflect what is going on in vivo.

Native HA is an important constituent of the glucosaminoglycan content of the intercellular matrix of the connective tissue (9). Because granulocytes and other cells of the lymphomyeloid system are surrounded by this matrix during parts of their life cycles and during the performance of their biological function in inflammations HA might exercise regulatory activities on these cells in vivo. The experimental finding that HA may produce either a stimulated or impaired PMN function raises the question whether HA may have a dual regulatory role in vivo. The recent demonstration that HA may be present in small amounts in the plasma (2) may indicate, in light of the present results, that $\mathrm{HA}$ as a humoral factor is involved in the multifactorial complex constituting natural resistance to infections. At high concentrations of $\mathrm{HA}$ as found in various connective tissue matrices, such as the joints (14), $\mathrm{HA}$ is supposed to reduce mobilization and reactivity of granulocytes and thereby control inflammatory events. Whether other proteoglycans found in connective tissue have qualities similar to those of HA, is unknown but an obvious possibility since polysaccharide components of bacterial capsules (e.g., glycan) (15) and several dextrans and dextran sulphates (16) are known 
to alter the host resistance to infections. By manipulating the dosage, route of injections, and experimental conditions, it is possible to demonstrate either an impaired or stimulated resistance to infections, after administration of the same compound. Administration of glycan or dextran sulphate to experimental animals is associated with an increase in weight and size of the major reticuloendothelial organs, presumably due to an increased number of activated macrophages. Whether HA also stimultes macrophages and the reticuloendothelial system in a manner similar to glycan or dextran sulphate is at present unknown.

The same HA preparations as used in this investigation have been tested in various pathological conditions. It has been reported that HA promotes the healing of vitreo-retinal wounds (17) and osteoarthritis after traumatic arthritis in racehorses (18). Preliminary studies have also indicated a beneficial effect of HA injections into knee joints in patients with rheumatoid arthritis (19). Our clinical experiences of HA on patients with impaired resistance to infections - which are reported elsewhere (20) - are promising but too incomplete for proper evaluation. Although we observed improvement of the clinical condition in conjunction with normalization of the neutrophil function, following the administration of $\mathrm{HA}$, the therapeutic effect of $\mathrm{HA}$ is difficult to substantiate because the natural course of disease in the patients studied is highly variable and unpredictable.

\section{ACKNOWLEDGMENTS}

This study was supported by the Swedish Medical Research Council, Gustaf V's 80 Year Foundation, and Pharmacia Fine Chemicals.

\section{REFERENCES}

1. Håkansson, L., R. Hällgren, and P. Venge. 1980. Effect of hyaluronic acid on phagocytosis of latex particles. Scand. J. Immunol. In press.

2. Murata, K. J., and Y. Horiuchi. 1977. Molecular weightdependent distribution of acidic glucosaminoglycans in human plasma. Clin. Chim. Acta. 75: 59-69.

3. Hällgren, R., L. Håkansson, and P. Venge. 1978. Kinetic studies of phagocytosis. I. The serum-independent particle uptake by PMNs from patients with rheumatoid arthritis and systemic lupus erythematosus. Arthritis Rheum. 21: 107-113.

4. Hällgren, R., L. Jansson, and P. Venge. 1977. Kinetic studies of phagocytosis of IgG-coated latex particles with a thrombocyte counter. J. Lab. Clin. Med. 90: 786-795.

5. MacGregor, R. R., P. J. Spagnuolo, and A. L. Lentnek.
1976. Inhibition of granulocyte adherence by ethanol, prednisone and aspirin measured with a new assay system. N. Engl. J. Med. 291: 642-646.

6. Zigmond, S. H., and J. G. Hirsch. 1973. Leucocyte locomotion and chemotaxis. New methods for evaluation, and demonstration of cell-derived chemotactic factor. J. Exp. Med. 137: 387-410.

7. Wilkinson, P. C. 1974. Chemotaxis and Inflammation. Churchill Livingstone, Edinburgh.

8. Venge, P., L. Håkansson, R. Hällgren, C. Pettersson, and G. Öberg. 1979. Continuous measurements of ATP and chemiluminescence in migrating and phagocytizing neutrophil granulocytes. Proceedings of the international symposium on analytical applications of bio- and chemiluminescence. E. Schram and P. Stanley, editors. State Printing and Publishing, Inc., Westlake Village, Calif. 560-581.

9. Balazs, E. A., and Z. Darzynkiewicz. 1973. The effect of hyaluronic acid on fibroblasts, mononuclear phagocytes and lymphocytes. In Biology of fibroblasts. E. Kulonen and J. Pikkarainen, editors. Academic Press, Inc., New York. 237-252.

10. Brandt, K. 1970. Modification of chemotaxis by synovial fluid hyaluronate. Arthritis Rheum. 13: 308-309.

11. Brandt, K. 1974. The effect of synovial hyaluronate on the ingestion of monosodium urate crystals by leukocytes. Clin. Chim. Acta. 55: 307-315.

12. Hällgren, R., and P. Venge. 1976. Cationic proteins of human granulocytes. Enhancement of phagocytosis of staphylococcus protein A-IgG complexes. Inflammation. 1: $237-242$.

13. Venge, P. 1979. Kinetic studies of cell migration in a modified Boyden chamber: dependence on cell concentration and effects of the chymotrypsin-like cationic protein of human granulocytes. J. Immunol. 122: 1180-1182.

14. Balazs, E. A. 1974. The physical properties of synovial fluid and the special role of hyaluronic acid. In Disorders of the Knee. J. P. Lippincott Company, Philadelphia. $63-75$.

15. Kokoshis, P. L., D. L. Williams, J. A. Cook, and N. R. Du Luzio. 1978. Increased resistance to Staphylococcus aureus infection and enhancement in serum lysozyme activity by glycan. Science (Wash. D. C.). 199: 1342-1344.

16. Bonventre, P. F., and B. Black-Shaffer. 1965. The effect of neutral and acidic polysaccarides on natural resistance of mice to bacterial challenge.J. Infect. Dis. 115: 413-420.

17. Balazs, E. A., M. I. Freeman, R. Klöti, G. Meyer-Schwickerath, F. Regnault, and D. B. Sweeney. 1973. In Modern Problems in Ophthalmology. 10: 3-21. S. Karger AG, Basel.

18. Åsheim, ̊., and G. Lindblad. 1976. Intraarticular treatment of arthritis in race-horses with sodium hyaluronate. Acta Vet. Scand. 17: 379-394.

19. Peyron, J. G., and E. A. Balazs. 1974. Preliminary clinical assessment of $\mathrm{Na}$-hyaluronate injection into human arthritis joints. Pathol. Biol. 22: 731-736.

20. Håkansson, L., R. Hällgren, P. Venge, G. Arthursson, and S. Vedung. 1979. Hyaluronic acid stimulates neutrophil function in vitro and in vivo. Scand. J. Infect. Dis. In press. 